(c) 2020 ФГБУ «НМИЦ ДГОИ им. Дмитрия Рогачева» Минздрава России

Поступила 7.09.2020 Принята к печати 30.09.2020

Контактная информация: Лаберко Александра Леонидовна, канд. мед. наук, научный сотрудник отдела оптимизации печения иммунодесицитов ФГБУ «НМИЦ ДГОИ им. Дмитрия Рогачева» Минздрава России Адрес: 117997, Москва ул. Саморы Машела, 1 E-mail: alexandra.laberko@gmail.com

DOI: $10.24287 / 1726-1708-2020-19-4$ suppl-30-38

Влияние клиникоиммунофенотипических вариантов тяжелой комбинированной иммунной недостаточности на тяжесть и исходы оппортунистических инфекций

А.Л. Лаберко, Ю.А. Родина, Е.В. Дерипапа, А.А. Роппельт, Д.В. Юхачева, Д.Е. Першин, Г.Г. Солопова, В.В. Бриллиантова, М.Ю. Алексенко, В.В. Захарова, Д.Н. Балашов, Г.А. Новичкова, А.Г. Румянцев, А.Ю. Щербина

ФГБУ «Национальный медицинский исследовательский центр детской гематологии, онкологии и иммунологии им. Дмитрия Рогачева» Минздрава России, Москва

Тяжелая комбинированная иммунная недостаточность (ТКИН) - это первичный иммунодесицит, который является тяжелым жизнеугрожающим заболеванием раннего возраста, в первую очередь за счет высокого риска развития плохо контролируемых инфекционных процессов. В данной работе проведен анализ структуры инфекционных процессов и прогноза заболевания в целом и в зависимости от клинико-иммунофенотипической формы ТКИН. Исследование одобрено локальным этическим комитетом и утверждено решением ученого совета НМИЦ ДГОИ им. Дмитрия Рогачева. В исследование включены 54 пациента с ТКИН, диагностированной в НМИЦ ДГОИ им. Дмитрия Рогачева с 2012 г. по июнь 2020 г. Медиана возраста на момент постановки диагноза составила 5,8 месяца. Все пациенты были разделены на 3 группы: классические формы ТКИН $(n=31)$; синдром Оменн $(n=11)$; ТКИН с материнским химеризмом $(n=12)$. По тяжести оппортунистических инфекций пациенты были разделены по принципу количества пораженных инфекционным процессом органов и тканей: без выделенных оппортунистических агентов или с поражением ими 1 органа ( $n=15)$; с поражением 2 органов $(n=17) ;$ с поражением 3 органов и более $(n=22)$. Из 46 БЦЖ-вакцинированных пациентов $22(48 \%)$ имели осложнения в виде БЦжинфекции: 16 - локальную и 6 - диссеминированную форму. При сравнении выраженности тяжелых инфекций между группами пациентов с различными формами ТКИН существенной разницы не получено $(p=0,22)$. Более тяжелые инфекции определялись у пациентов в возрастной группе старше 6 месяцев. Значения Т- и NK-лимфоцитов ниже медианы предрасполагали к более тяжелым инфекционным процессам только в группе пациентов с синдромом Оменн $(p=0,041)$. Больший риск БЦЖ-инфекции отмечался у пациентов с классической формой ТКИН, имеющих более низкий уровень NK-клеток $(p=0,009)$. Аллогенная трансплантация гемопоэтических стволовых клеток (ТГСК) проведена 45 пациентам. До проведения ТГСК погибли 9 пациентов с ТКИН и еще 21 после ТГСК от инфекционных осложнений и связанных с ними воспалительных синдромов. Таким образом, несмотря на некоторую роль Т- и NK-клеток в уменьшении тяжести оппортунистических инфекций при ТКИН, значимую роль в улучшении прогноза при данном заболевании имеет в первую очередь ранняя постановка диагноза.

Ключевые слова: тяжелая комбинированная иммунная недостаточность, синдром Оменн, материнский химеризм, оппортунистические инфекции, БЦЖ-инфекция, трансплантация гемопоэтических стволовых клеток

Лаберко А.Л. и соавт. Вопросы гематологии/онкологии и иммунопатологии в педиатрии. 2020; 19 (4 приложение): 30-38. DOI: 10.24287/1726-1708-2020-19-4suppl-30-38 


\section{Influence of clinical and immunophenotypic variants of severe combined immunodeficiency on severity and outcomes of opportunistic infections}

A.L. Laberko, Yu.A. Rodina, E.V. Deripapa, A.A. Roppelt, D.V. Yukhacheva, D.E. Pershin, G.G. Solopova, V.V. Brilliantova, M.Yu. Alexenko, V.V. Zakharova, D.N. Balashov, G.A. Novichkova, A.G. Rumyantsev, A.Yu. Shcherbina

Dmitry Rogachev National Medical Research Center of Pediatric Hematology, Oncology and Immunology Ministry of Healthcare of the Russian Federation, Moscow

Severe combined immunodeficiency (SCID) is a primary immunodeficiency that presents with life-threating symptoms in early infancy and has poor prognosis if not promptly treated. Here we present an analysis of infectious presentation and its course depending on clinical and immunophenotypic form of SCID. This study is supported by the Independent Ethics Committee and approved by the Academic Council of the Dmitry Rogachev National Medical Research Center of Pediatric Hematology, Oncology and Immunology. 54 patients were diagnosed with SCID in our center from 2012 to June 2020 and included to this study. The median age at diagnosis was 5.8 months. All patients were divided into 3 groups: classic SCID $(n=31)$; Omenn syndrome $(n=11)$; SCID with maternal fetal engraftment $(n=12)$. To determine opportunistic infections severity, based on a number of infected organs at disease presentation, 3 groups were formed: with no infections or 1 infected organ, $n=15$; with 2 infected organs $(n=15)$; with 3 and more infected organs $(n=22) .22$ of 46 BCG vaccinated patients $(48 \%)$ developed BCG-infection: 16 local and 6 disseminated. There was no difference in severity of infections between 3 groups of SCID ( $p=0.22)$, with more severe infections found in patients older than 6 months of age at diagnosis. T- and NK-cell numbers lower than median level predisposed to severer infections in Omenn syndrome patients $(p=0.041)$. There was a higher risk of BCG infections in classic SCID with low levels of NK-cells $(p=0.009) .45$ patients received allogeneic hematopoietic stem cell transplantation (HSCT). 9 patients died before HSCT and 21 after HSCT of infections and infections-related inflammatory syndromes. Though T- and NKcells might have a role in protecting from severe infections, the early diagnosis is the most important factor of better prognosis of SCID patients.

Key words: severe combined immunodeficiency, Omenn syndrome, maternal fetal engraftment, opportunistic infections, BCG infection, hematopoietic stem cell transplantation

Laberko A.L., et al. Pediatric Hematology/Oncology and Immunopathology. 2020; 19 (4 suppl): 30-38. DOI: 10.24287/1726-1708-2020-19-4suppl-30-38
(C) 2020 by «D. Rogachev NMRCPHOl» Received 7.09.2020 Accepted 30.09 .2020
Correspondence:

Alexandra L. Laberko,

MD, PhD, research associate, department of optimization of primary immunodeficiency treatment, Dmitry Rogachev National Medical Research Center of Pediatric Hematology, Oncology

and Immunology, Ministry of Healthcare of the Russian Federation Address: 1 Samory Mashela St.,

Moscow 117997, Russia

E-mail: alexandra.laberkoðgmail.com
$\Pi$ ервичные иммунодефицитные состояния (ПИДС) - это разнообразные генетические заболевания, при которых нарушены основные механизмы реализации функций иммунной системы. Клиническая картина ПИДС разнообразна и наиболее часто представлена инфекционными, аутоиммунными и опухолевыми процессами [1]. Тяжелая комбинированная иммунная недостаточность (ТКИН) - это группа ПИДС, в основе патогенеза которых лежит нарушение образования и дифференцировки Т-лимфоцитов [2]. В силу тяжести нарушения иммунного ответа при ТКИН ведущую роль в клинической картине играют тяжелые инфекции, вызванные в первую очередь оппортунистическими патогенами, которые при несвоевременной диагностике и отсутствии патогенетического лечения приводят к смерти пациентов в самом раннем возрасте.

Ввиду большого количества генетических дефектов, лежащих в основе ТКИН, иммунологические нарушения при данной патологии могут варьировать, формируя различный иммунофенотип заболевания. Несмотря на определяющий ТКИН дефект созревания и дифференцировки Т-лимфоцитов, у ряда пациентов в периферической крови может отмечаться нормальное или даже высокое их количество. Природа данного феномена неоднородна и ее определение крайне важно для выбора тактики лечения пациента [3]. Можно выделить 2 основных механизма возникновения Т-лимфоцитов у пациентов с ТКИН. Первый механизм наиболее характерен для синдрома Оменн, при котором происходит периферическая экспансия небольшого числа сформировав- шихся Т-лимфоцитов с образованием олигоклонов, имеющих, как следствие, очень ограниченный репертуар Т-клеточных рецепторов. Нарушение дифференцировки таких клеток не только не позволяет им эффективно бороться с инфекционными агентами, но и вследствие нарушения механизмов иммунной толерантности вызывает тяжелую аутоагрессию, что формирует типичную клиническую картину заболевания [4]. Синдром Оменн характеризуется генерализованной лимфопролиферацией (лимфаденопатией и гепатоспленомегалией), тяжелым распространенным дерматитом с алопецией, отечным синдромом и нередко поражением других органов и систем. Вторым механизмом появления Т-лимфоцитов в периферической крови пациентов с ТКИН является приживление и экспансия материнских клеток после их внутриутробного трансплацентарного проникновения от матери к плоду - так называемый материнский химеризм [5]. Чаще при данном сценарии Т-лимфоциты имеют более разнообразный репертуар Т-клеточных рецепторов, но ограниченный потенциал к пролиферации, поэтому такой Т-клеточный пул обычно истощается в течение нескольких месяцев после рождения. Нередко материнский химеризм Т-лимфоцитов при ТКИН приводит к такому осложнению, как материнская реакция «трансплантат против хозяина», когда ввиду HLA-несовместимости матери и ребенка происходит агрессия Т-лимфоцитов матери в отношении тканей организма ребенка, и, как следствие, к иммунному поражению различных органов.

Также стоит отметить, что иммунофенотип ТКИН характеризуется и наличием или отсутствием нату- 
ральных киллеров (NK) и В-лимфоцитов, в зависимости от генетически обусловленных дефектов созревания тех или иных популяций клеток. Поскольку В-лимфоциты в условиях отсутствия Т-клеток не способны к полноценной реализации своих функций, как В-позитивные, так и В-негативные формы ТКИН характеризуются выраженным нарушением специфического антителообразования, вносящего вклад в развитие тяжелых инфекционных процессов. Влияет ли наличие NK-клеток на развитие и тяжесть инфекций у ТКИН, в настоящее время достоверно не установлено.

Основной целью данной работы являлся анализ структуры инфекционных процессов и их исходов в зависимости от формы ТКИН. Поскольку именно Т- и, предположительно, NK-лимфоциты играют ведущую роль в иммунном ответе на оппортунистические инфекционные агенты, одной из задач исследования также являлось выявление связи тяжести оппортунистических инфекций с наличием или отсутствием различных популяций лимфоцитов у пациентов с ТКИН.

\section{МАТЕРИАЛЫ И МЕТОДЫ ИССЛЕДОВАНИЯ}

Исследование одобрено локальным этическим комитетом и утверждено решением ученого совета НМИЦ ДГОИ им. Дмитрия Рогачева. В данное иссле-
Рисунок 1

Генетические варианты ТКИН $(n=54)$

Figure 1

Genetic variants of severe combined immunodeficiency (SCID) $(n=54)$

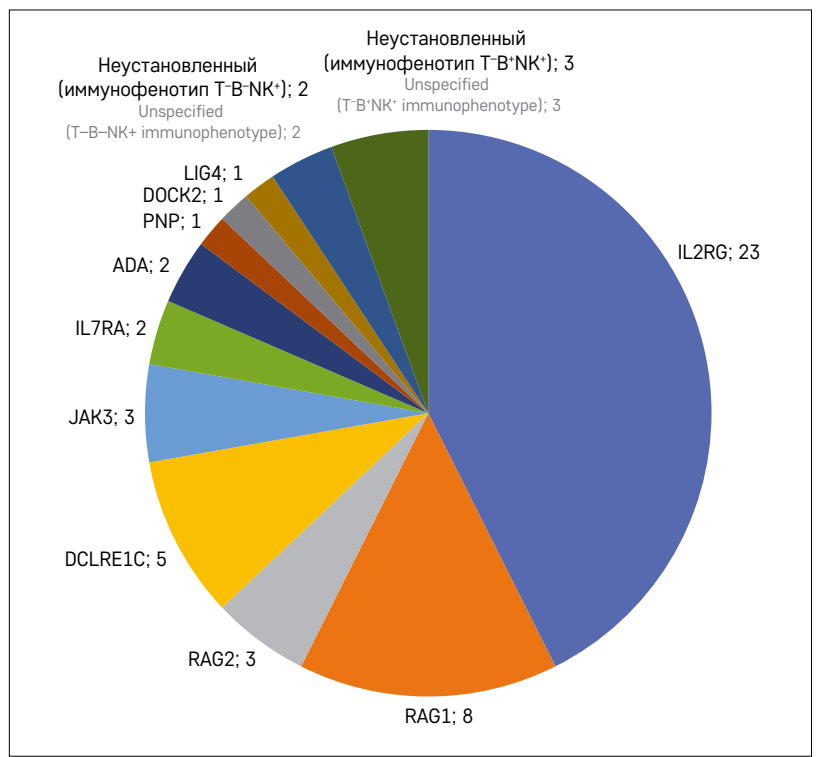

дование включены 54 пациента с ТКИН, получавших терапию в ФГБУ «НМИЦ ДГОИ им. Дмитрия Рогачева» Минздрава России с 2012 г. до июня 2020 г. Диагноз ТКИН устанавливали в соответствии с Национальными клиническими рекомендациями [6], у 49 пациентов впоследствии он был подтвержден при

\section{Таблица 1}

Распределение по возрасту, полу и генетическим вариантам в группах ТКИН с классическим фенотипом, синдромом Оменн и материнским химеризмом

Table 1

Distribution by age, sex and genetic variant in patients from the following SCID groups: classic SCID, Omenn syndrome, SCID with maternal fetal engraftment (MFE)

\begin{tabular}{|c|c|c|c|c|}
\hline $\begin{array}{l}\text { Характеристика } \\
\text { Characteristics }\end{array}$ & $\begin{array}{c}\text { Классические ТKИН } \\
\text { Classic SCID }\end{array}$ & $\begin{array}{l}\text { Синдром Оменн } \\
\text { Omenn syndrome }\end{array}$ & $\begin{array}{l}\text { ТКИН с материнским } \\
\text { химеризмом } \\
\text { SCID with } \\
\text { MFE }\end{array}$ & $\underset{p \text {-value }}{p \text {-значение }}$ \\
\hline $\begin{array}{l}\text { Число пациентов, } n \\
\text { Number of patients, } n\end{array}$ & 31 & 11 & 12 & - \\
\hline $\begin{array}{l}\text { Медиана возраста появления первых } \\
\text { симптомов (разброс), месяцы } \\
\text { Median age at the onset of the first symptoms } \\
\text { (range), months }\end{array}$ & $3(0-17)$ & $1(0-15)$ & $3(0,7-8)$ & 0,2 \\
\hline $\begin{array}{l}\text { Медиана возраста на момент постановки } \\
\text { диагноза (разброс), месяцы } \\
\text { Median age at diagnosis (range), months }\end{array}$ & $7,2(1,0-31,8)$ & $3,0(0,9-15,1)$ & $8,1(3,5-15,2)$ & 0,007 \\
\hline $\begin{array}{l}\text { Соотношение по полу, мальчики:девочки } \\
\text { Sex ratio (male:female ratio) }\end{array}$ & $21: 10$ & $7: 4$ & $7: 5$ & 0,93 \\
\hline \multicolumn{5}{|c|}{$\begin{array}{l}\text { Генетические дефекты } \\
\text { Genetic defects }\end{array}$} \\
\hline IL2RG & 16 & - & 7 & \\
\hline RAG1 & 2 & 6 & - & \\
\hline RAG2 & - & 2 & 1 & \\
\hline DCLRE1C & 4 & 1 & - & \\
\hline$J A K 3$ & 1 & 1 & 1 & \\
\hline IL7RA & - & - & 2 & \\
\hline$A D A$ & 2 & - & - & \\
\hline DOCK2 & 1 & - & - & \\
\hline$P N P$ & 1 & - & - & \\
\hline LIG4 & 1 & - & - & \\
\hline 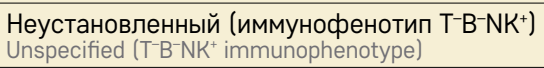 & - & 1 & 1 & \\
\hline 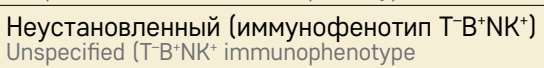 & 3 & - & - & \\
\hline
\end{tabular}


молекулярно-генетическом исследовании отдельных генов методом полимеразной цепной реакции (ПЦР) и прямого бидирекционного секвенирования по Сэнгеру или в панелях генов ПИДС методом секвенирования нового поколения. Генетические варианты ТКИН представлены на рисунке 1.

Для определения числа Т- и NK-лимфоцитов проводилось иммунофенотипирование лейкоцитов периферической крови пациентов методом проточной цитометрии. Для Т-лимфоцитов использовался маркер $\mathrm{CD}^{+}$, для NK-клеток - CD3-16+56+. Исследование материнского химеризма проводилось методом ПЦР посредством определения коротких тандемных повторов в Т-лимфоцитах с фенотипом $\mathrm{CD}^{+}$в крови пациентов с ТКИН и их матерей. Данное исследование проводилось только при определяемых в периферической крови Т-лимфоцитах по данным иммунофенотипирования лейкоцитов.

На основании характерной клинико-лабораторной картины заболевания и проводимого исследования материнского химеризма все пациенты в данном исследовании были разделены на 3 группы: 1-я классические формы ТКИН без признаков синдрома Оменн и материнского химеризма $(n=31), 2-я-$ ТКИН с синдромом Оменн $(n=11)$ и 3-я - ТКИН с материнским химеризмом ( $n=12)$. Структура возраста на момент постановки диагноза ТКИН, пола и генетических вариантов ТКИН в 3 группах представлена в таблице 1.

Структура инфекционных процессов для анализа в подгруппах формировалась на основании количества пораженных органов и тканей. Помимо бактериологических и грибковых культуральных исследований сред организма всем пациентам в целях поиска очагов оппортунистических инфекций проводились рутинные исследования крови и стула методом ПЦР на выявление вирусов группы герпеса (цитомегаловирус, вирус Эпштейна-Барр (ЭБВ) и вирус герпеса 6-го типа) и кишечных вирусов (ротавирус, норовирус, астровирус, аденовирус). Всем пациентам с ТКИН (за исключением пяти) рутинно проводилось микробиологическое исследование бронхоальвеолярного лаважа или аспирата трахеобронхиального дерева с поиском широкого спектра патогенов методом ПЦР (панели групп респираторных и герпесвирусов, микобактериальный комплекс, Pneumocystis jiroveci), а также галактоманнанового антигена. Также по показаниям при признаках инфекционного поражения других органов у ряда пациентов дополнительно исследовались и другие биологические жидкости, преимущественно спинномозговая и внутриглазная.

Отдельным важным оппортунистическим патогеном у ТКИН является вакцинальный штамм Mycobacterium bovis. Анализ рисков БЦЖ-инфекции проводился у 46/54 (85\%) пациентов, которые были вакцинированы БЦЖ до момента постановки диагноза (в основном после рождения).

Важно отметить, что не всегда выделение микроорганизмов из сред организма сочеталось с клиническими, инструментальными или лабораторными признаками поражения органа. Однако ввиду неспособности пациентов с ТКИН формировать активные очаги воспаления в месте инфицирования рядом патогенов, а также низкой вероятности полной элиминации инфекционных агентов до трансплантации гемопоэтических стволовых клеток (ТГСК), такие инфекционные процессы при определении их тяжести также учитывались как клинически значимые.

Статистическая обработка данных проводилась при помощи программы XLSTAT 2015 (Addinsoft, Франция). Для оценки р-значений при сравнении количественных переменных использованы тесты Манна-Уитни и Крускала-Уоллиса, категориальных переменных - точный критерий Фишера в таблицах сопряженности.

\section{РЕЗУЛЬТАТЫ ИССЛЕДОВАНИЯ}

\section{Тяжесть оппортунистических инфекций}

Помимо колонизации большинства пациентов патогенной микрофлорой (чаще нозокомиальными штаммами) у 45/54 пациентов минимум в 1 среде организма были выявлены различные вирусы, у 16 определялись Pneumocystis jiroveci, у 11 грибковые агенты. Важно отметить, что у 2 пациентов ЭБВ-инфекция привела к развитию такого редкого осложнения ТКИН, как лимфома [7]. Структура инфекционных осложнений представлена на рисунке $2 A$.

Для градации тяжести инфекционного процесса все пациенты были разделены по принципу количества пораженных оппортунистическими инфекциями органов и тканей. В 1-ю группу включены пациенты без выделенных оппортунистических агентов или с поражением ими 1 органа ( $n=15)$, во 2-ю - с поражением 2 органов $(n=17)$ и в $3-ю-3$ органов и более ( $n=22)$ (рисунок 25). Распределение по тяжести инфекций при различных формах ТКИН представлено в таблице 2. Несмотря на меньшее число пациентов с обширными инфекциями в группе с синдромом Оменн и большее количество тяжелых инфекций в группе классических ТКИН, статистически значимой разницы при сравнении тяжести инфекций между группами не получено ( $p=0,22)$.

Медиана возраста на момент постановки диагноза у 54 пациентов, включенных в исследование, составила 5,9 (разброс 0-31,8) месяца, при том что медиана возраста первых симптомов ТКИН - 
всего 3 (разброс 0-17) месяца (таблица 1). Особенно выражена задержка постановки диагноза в группах ТКИН с классическим фенотипом и материнским химеризмом ( $p=0,0001$ и $p=0,001$ соответственно против $p=0,053$ у пациентов с синдромом Оменн).

В группе пациентов, у которых ТКИН диагностирован до 6 месяцев жизни, отмечалось меньше тяжелых инфекций, чем в группе более старших пациентов $(p=0,076)$ (таблица 2). Учитывая статистически значимый меньший возраст на момент диагноза в группе пациентов с синдромом Оменн по отношению к группам ТКИН с классическим фенотипом и материнским химеризмом ( $p=0,007)$ (таблица 1), нельзя исключить и меньшее количество тяжелых инфекций в группе больных с синдромом Оменн именно за счет их более раннего возраста.

При оценке влияния значений T- и NK-лимфоцитов периферической крови на тяжесть инфекций в отдельных группах ТКИН все пациенты были условно разделены на 2 группы: со значениями Т- и NK-лимфоцитов выше и ниже медианы в каждой группе ТКИН. Медианы и разброс значений Т- и NK-клеток в периферической крови пациентов в группах ТКИН представлены в таблице 3. Как следует из патогенеза заболеваний, более высокие значения T- и NK-лимфоцитов имели пациенты с синдромом Оменн. У пациентов с ТКИН с материнским химеризмом Т-лимфоциты определялись, но в более низких значениях, при классических формах ТКИН уровни Т-лимфоцитов были крайне низкими или чаще не определялись совсем. При анализе влияния уровня Т-и NK-клеток на тяжесть оппортунистических инфекций статистически значимая разница была получена лишь для группы пациентов с синдромом Оменн: более низкие значения как Т-, так и NK-лимфоцитов предрасполагали к более тяжелым инфекционным процессам ( $p=0,041)$. В группах пациентов с классической формой ТКИН и материнским химеризмом данная тенденция не прослеживалась $(p=0,76-1,0)$.

\section{БЦЖ-инфекции}

Из 46 БЦЖ-вакцинированных пациентов 22 (48\%) на разных этапах жизни имели осложнения в виде БЦЖ-инфекции: 16 - локальную форму (у всех воспалительные явления в месте вакцинации, которые у 3 пациентов сопровождались регионарной лимфаденопатией) и 6 - диссеминированную форму с поражением различных органов и тканей. У 14 пациентов БЦЖ-инфекция манифестировала к моменту госпитализации и еще у 8 - после проведенной аллогенной ТГСК.

Риски развития БЦЖ-инфекции в группах ТКИН представлены в таблице 4. Несмотря на меньшую долю БЦЖ-инфекций в группе пациентов с синдромом Оменн, статистически значимой разницы при сравнении частоты БЦЖ-инфекций при разных формах ТКИН не получено $(p=0,31)$. При оценке влияния

\section{Рисунок 2}

Структура инфекционных осложнений при ТКИН ( $n=54)$ : А - выделяемые инфекционные агенты; Б - тяжесть инфекционного процесса

*Грибковые агенты (моноинфекция - 8, сочетание 2 инфекций - 2): Candida bracarensis - 1, Candida parapsilosis - 3, Candida albicans - 1, Candida tropicalis - 1, Candida glabrata - 1, Aspergillus fumigatus - 4, Aspergillus nidulans - 1. Кишечные вирусы (моноинфекция - 18, сочетание 2 инфекций - 3, более 2 инфекций - 1): ротовирус - 12, норовирус - 12, астровирус - 2, аденовирус - 1. Герпесвирусы (моноинфекция - 22, сочетание 2 инфекций -5 ): цитомегаловирус - 20, ЭБВ - 6, вирус герпеса 6-го типа - 6. Респираторные вирусы (моноинфекция- 14, сочетание 2 инфекций - 7, более 2 инфекций - 5): риновирус - 18, бокавирус - 3, метапневмовирус - 2, аденовирус - 2, коронавирус - 2, вирус парагриппа 3-го типа - 8, вирус парагриппа 4-го типа - 1 , респираторно-синцитиальный вирус-7. Другие вирусы: ВК-вирус - 1, парвовирус В19-1

Figure 2

The distribution of infectious complications in patients with SCID ( $n=54)$ : A -identified infectious agents; B - the severity of the infectious process

"Fungal agents (monoinfection - 8, combination of two infections - 2): Candida bracarensis - 1, Candida parapsilosis - 3, Candida albicans - 1, Candida tropicalis - 1, Candida glabrata - 1, Aspergillus fumigatus - 4, Aspergillus nidulans - 1. Enteric viruses (monoinfection - 18, combination of two infections - 3, more than two infections - 1 ): rotavirus - 12, norovirus - 12, astrovirus - 2, adenovirus - 1 . Herpesviruses (monoinfection - 22, combination of two infections -5 ): cytomegalovirus -20 , Epstein-Barr virus - 6, human herpesvirus $6-6$. Respiratory viruses (monoinfection - 14, combination of two infections -7 , more than two infections -5 ): rhinovirus -18 , bocavirus -3 , metapneumovirus -2 ,
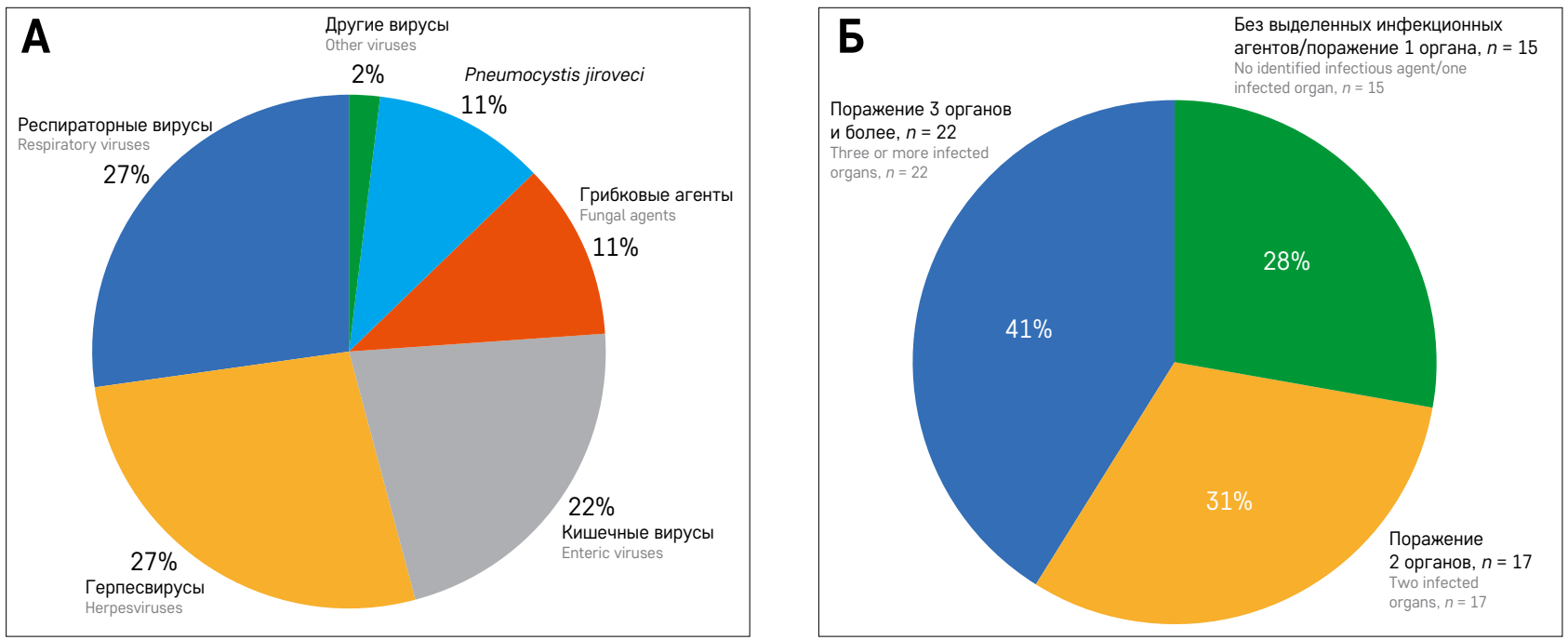
значений T- и NK-лимфоцитов выше и ниже медианы на риск развития БЦЖ-инфекции больший риск отмечался у пациентов с классической формой ТКИН, имеющих более низкие уровни $\mathrm{NK}$-клеток $(p=0,009)$. В группах пациентов с синдромом Оменн и материнским химеризмом данная тенденция не прослеживалась $(p=0,55-1,0)$. Значимой разницы риска БЦЖ-инфекции в зависимости от уровней Т-лимфоцитов также не отмечалось ни в одной из исследуемых групп ( $p=0,14-1,0)$.

\section{Смертность}

Аллогенная ТГСК проведена 45 из 54 пациентов, 9 больных погибли от инфекционных осложнений до проведения трансплантации и еще 21 - после. Причинами смерти пациентов с ТКИН после ТГСК являлись: у 7 - инфекции, вызванные нозокомиальными штаммами бактериальных агентов, у 6 - инфекции, вызванные вирусными агентами, у 1 - грибковый сепсис, у 7 - полиорганная недостаточность на фоне воспалительных синдромов восстановления иммунной системы после ТГСК (рисунок 3).

При оценке влияния тяжести инфекционных процессов на момент диагноза на риск смертности пациентов наибольшая смертность отмечалась среди больных с поражением более 2 органов $(p=0,09)$. При анализе по группам ТКИН распространенная инфекция значимо повышала риск смерти у паци-

Таблица 2

Распределение пациентов по тяжести оппортунистических инфекций в группах ТКИН с классическим фенотипом, синдромом Оменн и материнским химеризмом

Table 2

Distribution by the severity of opportunistic infections in patients from the following SCID groups: classic SCID, Omenn syndrome, SCID with MFE

\begin{tabular}{|c|c|c|c|c|c|c|}
\hline \multirow[b]{2}{*}{$\begin{array}{l}\text { Тяжесть инфекции } \\
\text { Severity of infection }\end{array}$} & \multicolumn{3}{|c|}{$\begin{array}{l}\text { Форма ТКИН } \\
\text { Form of SCID }\end{array}$} & \multicolumn{2}{|c|}{$\begin{array}{c}\text { Возраст на момент постановки } \\
\text { диагноза TKИН } \\
\text { Age at the diagnosis of SCID }\end{array}$} & \multirow[b]{2}{*}{$\begin{array}{l}\text { Живы/ } \\
\text { умерли } \\
\text { Alive/dead }\end{array}$} \\
\hline & $\begin{array}{c}\text { классические ТКИН } \\
(n=31) \\
\text { Classic SCID } \\
(n=31)\end{array}$ & $\begin{array}{c}\text { синдром Оменн, } \\
(n=11) \\
\text { Omenn syndrome } \\
(n=11)\end{array}$ & $\begin{array}{l}\text { ТКИН с материнским } \\
\text { химеризмом }(n=12) \\
\text { SCID with MFE } \\
(n=12)\end{array}$ & $\begin{array}{c}\text { менее } \\
6 \text { месяцев } \\
(n=26) \\
\text { younger than } \\
6 \text { months } \\
(n=26)\end{array}$ & $\begin{array}{c}\text { более } \\
6 \text { месяцев, } \\
(n=28) \\
\text { older than } \\
6 \text { months } \\
(n=28)\end{array}$ & \\
\hline $\begin{array}{l}\text { Поражение } \\
0-1 \text { органа } \\
0-1 \text { infected organ }\end{array}$ & 6 & 6 & 3 & 11 & 4 & $8 / 7$ \\
\hline $\begin{array}{l}\text { Поражение } \\
2 \text { opганов } \\
2 \text { infected organs }\end{array}$ & 10 & 2 & 5 & 7 & 11 & $10 / 8$ \\
\hline $\begin{array}{l}\text { Поражение } \\
3 \text { органов и более } \\
3 \text { infected organs }\end{array}$ & 15 & 3 & 4 & 8 & 13 & $5 / 16$ \\
\hline
\end{tabular}

\section{Таблица 3}

Медианы и разброс Т- и NK-клеток в периферической крови пациентов в группах ТКИН с классическим фенотипом, синдромом Оменн и материнским химеризмом

Table 3

The median and range of T- and NK-cells values in the peripheral blood of patients from the following SCID groups: classic SCID, Omenn syndrome, SCID with MFE

\begin{tabular}{|c|c|c|c|c|}
\hline $\begin{array}{l}\text { Параметр } \\
\text { Parameter }\end{array}$ & $\begin{array}{c}\text { Классические ТКИН } \\
(n=31) \\
\text { Classic SCID } \\
(n=31)\end{array}$ & $\begin{array}{c}\text { Синдром Оменн } \\
(n=11) \\
\text { Omenn syndrome }(n=11)\end{array}$ & $\begin{array}{c}\text { Материнский химеризм } \\
(n=12) \\
\text { SCID with MFE (n=12) }\end{array}$ & $\begin{array}{c}\text { Референсные } \\
\text { значения* } \\
\text { Reference values* }\end{array}$ \\
\hline $\mathrm{CD3}^{+}, \times 10^{9} / л$ & $0,09(0-2,85)$ & $1,6(0,06-26,4)$ & $0,26(0-10,0)$ & $2,28-6,45$ \\
\hline $\mathrm{CD}^{-}-16^{+} 56^{+}$, × 109/ת & $0,1(0-8,0)$ & $0,51(0-5,5)$ & $0,1(0-2,3)$ & $0,1-0,92$ \\
\hline
\end{tabular}

Примечание. Уровни $C D 3^{+}$и CD3-16+56+-лимфоцитов не оценивались у 2 пациентов 1 - с классической формой ТКИН и $1-c$ TKИН с материнским химеризмом) и уровень CD3-16+56+-лимфоцитов не оценивался еще у 1 пациента с классической формой ТКИН. *- валидированы лабораторией в НМИЦ ДГОИ им. Дмитрия Рогачева

Note. The levels of CD3+ and CD3-16+56+-lymphocytes were not assessed in 2 patients (one patient had classic SCID and the other patient had SCID with maternal fetal engraftment) 列

\section{Таблица 4}

Частота и особенности БЦЖ-инфекции в группах ТКИН с классическим фенотипом, синдромом Оменн и материнским химеризмом

Table 4

The frequency and forms of BCG infection in patients from the following SCID groups: classic SCID, Omenn syndrome, SCID with MFE

\begin{tabular}{|c|c|c|c|}
\hline $\begin{array}{l}\text { Группа } \\
\text { Group }\end{array}$ & $\begin{array}{c}\text { Классические ТКИН } \\
\text { Classic SCID }\end{array}$ & $\begin{array}{l}\text { Синдром Оменн } \\
\text { Omenn syndrome }\end{array}$ & $\begin{array}{l}\text { TКИН с материнским химеризмом } \\
\text { SCID with MFE }\end{array}$ \\
\hline $\begin{array}{l}\text { БЦЖ-вакцинация } \\
\text { BCG vaccination }\end{array}$ & 24 & 10 & 12 \\
\hline $\begin{array}{l}\text { БЦЖ-инфекция } \\
\text { BCG infection }\end{array}$ & $\begin{array}{l}14(Л-9, D-5) \\
14(L-9, D-5)\end{array}$ & $\begin{array}{l}3(\Omega-3) \\
3(L-3)\end{array}$ & $\begin{array}{l}5(\Omega-4, Д-1) \\
5(L-4, D-1)\end{array}$ \\
\hline
\end{tabular}

Примечание. Л-локальная, Д-диссеминированная.

Note. $L$ - local, $D$-disseminated. 
Рисунок 3

Структура смертности пациентов с ТКИН после ТГСК $(n=21)$

Figure 3

The structure of mortality in patients with SCID after HSCT $(n=21)$

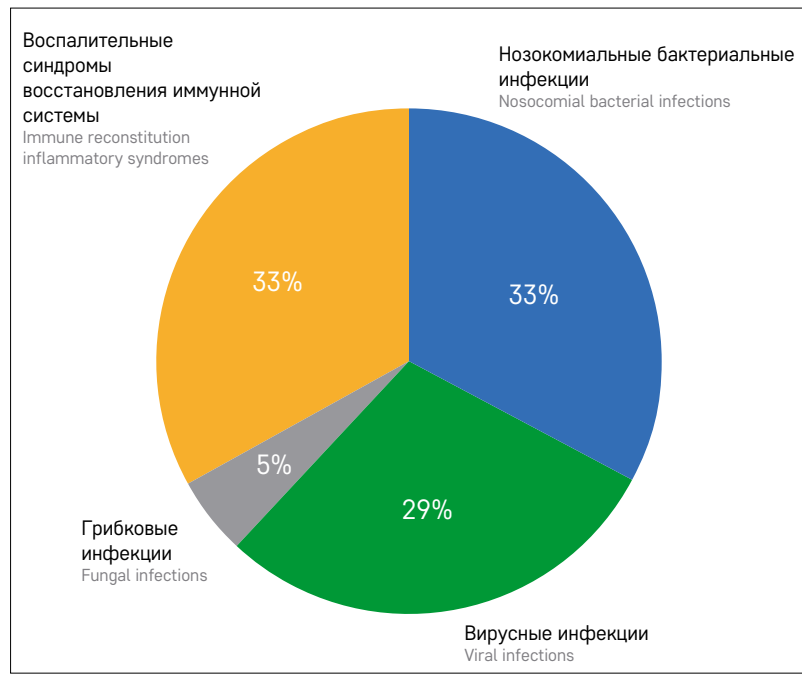

ентов с классической формой, где из 15 умерших 11 имели инфекционное поражение более 2 органов и тканей $(p=0,01)$. Уровни Т-лимфоцитов выше и ниже медианы в различных группах ТКИН на момент диагноза никак не влияли на риски смерти пациентов $(p=0,5-0,8)$.

\section{ОБСУЖДЕНИЕ РЕЗУЛЬТАТОВ ИССЛЕДОВАНИЯ}

ТКИН является тяжелым жизнеугрожающим заболеванием, высокая ранняя летальность которого обусловлена в первую очередь развитием плохо контролируемых инфекционных процессов. Данное исследование оценивало фенотипические факторы риска развития тяжелых инфекций и их влияние на прогноз заболевания при различных формах ТКИН.

Известно, что основным фактором, определяющим прогноз заболевания при ТКИН, является возраст диагностики и, как следствие, возраст проведения аллогенной ТГСК как единственного широкодоступного метода радикальной терапии ТКИН [8]. Также неоднократно показано, что пациенты с ТКИН с активными инфекционными процессами на момент ТГСК имеют худшие показатели выживаемости $[8,9]$. Безусловно, эти фракторы напрямую связаны между собой, что в том числе показывают и результаты нашего исследования: возраст диагностики ТКИН коррелирует с тяжестью оппортунистических инфекций. Необходимо отметить, что медианой диагностики ТКИН у наших пациентов являлся возраст 6 месяцев, тогда как, по данным Раі и соавт., худший прогноз выживаемости после ТГСК имеют больные, которым трансплантация проведена уже в возрасте старше 3,5 месяца [8]. К сожалению, за исключением паци- ентов с синдромом Оменн, когда подозрение на данное заболевание нередко возникает на основании характерной клинической картины зачастую до развития у пациентов тяжелых инфекционных процессов, большинству больных с ТКИН в России диагноз устанавливается только после перенесенных ими тяжелых, нередко многократных инфекционных процессов [10]. Значимая задержка постановки диагноза, особенно при ТКИН с классическим фенотипом и материнским химеризмом, прослеживается и в нашем исследовании. Именно поздняя диагностика ТКИН и отягощенный инфекционный статус пациентов на момент ТГСК обусловливают такую высокую посттрансплантационную летальность в данном исследовании - около $50 \%$. Важно отметить, что все пациенты, получившие ТГСК, погибли от инфекционных осложнений или связанных с инфекциями синдромов восстановления иммунной системы. Показатели выживаемости после ТГСК у пациентов с ТКИН являются значимо более низкими, чем при других нозологических формах ПИДС в нашем Центре [11], а также худшими, чем могут обеспечивать современные технологии ТГСК для больных ТКИН $[9,12]$.

Одной из целей исследования являлось определение возможной роли Т- и NK-лимфоцитов в уменьшении тяжести инфекционных процессов при различных формах ТКИН. Несмотря на полученную нами статистическую значимость более низких уровней T- и NK-лимфоцитов у пациентов с развитием тяжелых инфекций в группе с синдромом Оменн, следует отметить, что анализ проводился на малой выборке $(n=11)$, где в силу более раннего возраста диагностики в принципе отмечалось меньше тяжелых инфекционных процессов в сравнении с другими группами ТКИН. Для ТКИН с классическим фенотипом и материнским химеризмом такой тенденции не прослеживалось. Также интересно, что при проведении подобного анализа в отношении риска БЦЖ-инфекции схожих результатов для группы синдрома Оменн получено не было. Таким образом, вероятно, Т- и NK-лимфоциты у пациентов с ТКИН в силу ограниченности своего репертуара не имеют протективного эффекта в отношении оппортунистических инфекционных агентов. Однако для подтверждения данного утверждения необходимо проведение более детального анализа на больших группах пациентов.

В соответствии с Национальным календарем профилактических прививок России вакцинация БЦЖ при отсутствии противопоказаний проводится всем здоровым новорожденным с 3-го по 7-й день жизни [13]. Необходимо заметить, что структура и частота осложнений БЦЖ-вакцинации в России практически не отражены в научных источниках, а сравнение данных с зарубежными исследованиями может быть ограничено особенностями различных штаммов БЦЖ-вакцин, 
применяемых в разных странах. Учитывая нормальный соматический статус при рождении и возникающее подозрение на ТКИН у большинства пациентов в более старшем возрасте, 85\% больных в нашем исследовании получили вакцинацию БЦЖ после рождения. Около половины БЦЖ-вакцинированных пациентов с ТКИН имели осложнения в виде развития БЦЖ-инфекции, что соответствует данным крупного международного мультицентрового исследования [14], хотя в нашей группе отмечалось меньше диссеминированных форм. Также Marciano и соавт. определили более высокий риск развития БЦЖ-осложнений у пациентов с классическими формами ТКИН с более низким уровнем Т-лимфоцитов [14]. Интересно, что нами не было получено разницы в риске развития БЦЖ-инфекции в зависимости от уровня Т-лимфоцитов как при классических формах ТКИН, так и при синдроме Оменн и ТКИН с материнским химеризмом. Возможно, наш анализ компрометирован более низкими значениями Т-лимфоцитов в группе ТКИН с классическим фенотипом (медиана Т-лимфоцитов в данной группе пациентов в нашем исследовании составила 0,09 × 10\%/л, тогда как пороговым значением для риска БЦЖ-инфекции у Marciano и соавт. считалось 0,25 × 10\%/л). Польские исследователи недавно продемонстрировали более высокий риск диссеминированных форм БЦЖ-инфекции при NK-негативных формах ТКИН [15]. Нами также был получен больший риск БЦЖ-осложнений при низких уровнях NK-лимфоцитов в группе классических форм ТКИН. Интересно, что в нашем исследовании при этом пациенты с низкими уровнями NK-клеток имели выше риск не только диссеминированных, но и локальных форм. Важно отметить, что хотя непосредственной причиной смерти пациентов В данном исследовании не являлась БЦЖ-инфекция, но, как мы описывали ранее, и сама диссеминированная БЦЖ-инфекция, и нередко развивающиеся после ТГСК БЦЖ-ассоциированные синдромы восстановления иммунной системы значимо повышают морбидность и риск летальности от сопутствующих проблем [16].

Безусловно, данное исследование имеет ряд ограничений. Во-первых, ТКИН является редким генетическим заболеванием и ввиду плохой диагностики данного состояния специалистами на местах в профильные учреждения России попадает лишь малая часть больных [17], в силу чего статистический анализ показателей проводился на малых выборках. Во-вторых, генетическая природа ТКИН в данной выборке крайне неоднородна, а у нескольких пациентов до сих пор является не установленной. Данные крупных международных исследований указывают на то, что при схожей клинической картине ряд генетических форм ТКИН могут иметь свои особенности фенотипа [18]. Например, ряд исследователей, несмотря на выполнение клинических критериев ТКИН, дефицит DOCK2 и РNP, выделяют в группу комбинированных ПИДС пациентов с менее тяжелым течением, чем у других ТКИН [19]. Также важно отметить, что определение истинной картины инфекционных осложнений при ТКИН является затруднительным в силу отсутствия у таких больных полноценного иммунного ответа и, как следствие, неформирующихся очагов воспаления в органах и тканях. Данный феномен особенно хорошо отражает такая особенность ТКИН после аллогенных ТГСК, как развитие воспалительных синдромов восстановления иммунной системы [16], более полно описанный у ВИЧ-инфицированных пациентов с синдромом приобретенного иммунодефицита [20].

Своевременная диагностика ТКИН крайне важна, так как максимально рано назначенная противомикробная профилактика и аллогенная ТГСК, проведенная до инфицирования пациента множественными оппортунистическими патогенами, значимо увеличивают выживаемость данных больных. Важной мерой по раннему выявлению ТКИН в различных странах Европы и США является неонатальный скрининг [21]. По данным Heimall и соавт., раннее выявление ТКИН посредством неонатального скрининга и проведение ТГСК до развития инфекций позволяют улучшить показатели выживаемости данных пациентов до 95\% [9]. Целесообразность неонатального скрининга ТКИН в России демонстрируют и ряд отечественных исследователей [22]. Однако на данный момент в условиях отсутствия возможности проведения массового неонатального скрининга в России своевременная диагностика ТКИН ложится на плечи врачей-педиатров. Крайне важной является настороженность специалистов в отношении наличия у пациентов ТКИН при развитии осложнений БЦЖ-вакцинации, любых тяжелых инфекционных процессов, особенно вызванных оппортунистическими патогенами, тяжелых дерматитов и диареи, а также обнаружении лимфопении и гипогаммаглобулинемии [6]. При этом необходимо помнить, что отдельные формы ТКИН, такие как синдром Оменн и ТКИН с материнским химеризмом, могут иметь и нормальные или даже высокие значения Т-лимфоцитов. Также особо важен семейный анамнез, настораживающий в отношении наличия ПИДС и особенно ранних смертей в семье [10]. Отягощенный семейный анамнез должен являться основанием для отсрочки БЦЖ-вакцинации до исключения у ребенка ПИДС.

\section{ЗАКЛЮЧЕНИЕ}

ТКИН является тяжелым жизнеугрожающим заболеванием у детей раннего возраста. Своевременная диагностика до развития у пациентов тяжелых инфекционных процессов существенно улучшает прогноз 
выживания данной группы больных. Важной мерой для ранней диагностики пациентов с ТКИН является внедрение неонатального скрининга.

\section{ИСТОЧНИК ФИНАНСИРОВАНИЯ}

Не указан.

\section{КОНФЛИКТ ИНТЕРЕСОВ}

Авторы статьи подтвердили отсутствие конфликта интересов, о котором необходимо сообщить.
ORCID

Laberko A.L. ORCID: http://orcid.org/0000-0002-2354-2588

Rodina Yu.A. ORCID: http://orcid.org/0000-0001-9857-4456

Deripapa E.V. ORCID: http://orcid.org/0000-0002-9083-4783

Roppelt A.A. ORCID: http://orcid.org/0000-0001-5132-1267

Yukhacheva D.V. ORCID: http://orcid.org/0000-0001-9078-8206

Pershin D.E. ORCID: http://orcid.org/0000-0002-6148-7209

Solopova G.G. ORCID: http://orcid.org/0000-0002-1680-7269

Brilliantova V.V. ORCID: http://orcid.org/0000-0003-0079-7761

Alexenko M.Yu. ORCID: https://orcid.org/0000-0002-2521-5353

Zakharova V.V. ORCID: https://orcid.org/0000-0001-5949-5317

Balashov D.N. ORCID: http://orcid.org/0000-0003-2689-0569

Novichkova G.A. ORCID: http://orcid.org/0000-0002-2322-5734

Rumyantsev A.G. ORCID: http://orcid.org/0000-0003-1643-5960

Shcherbina A.Yu. ORCID: http://orcid.org/0000-0002-3113-4939

\section{Литература}

1. Кузьменко Н.Б., Щербина А.Ю. Классификация первичных иммунодефицитов как отражение современных представлений об их патогенезе и терапевтических подходах. Российский журнал детской гематологии и онкологии 2017; 4 (3): 51-7.

2. van der Burg M., Gennery A.R. Educational paper: The expanding clinical and immunological spectrum of severe combined immunodeficiency. Eur J Pediatr 2011; 170 (5): 561-71.

3. Shearer W.T., Dunn E., Notarangelo L.D., Dvorak C.C., Puck J.M., Logan B.R., et al. Establishing diagnostic criteria for severe combined immunodeficiency disease (SCID), leaky SCID, and Omenn syndrome: The Primary Immune Deficiency Treatment Consortium experience. J Allergy Clin Immunol2014; 133 (4): 10928.

4. Marrella V., Maina V., Villa A. Omenn syndrome does not live by $V(D) J$ recombination alone: Curr Opin Allergy Clin Immunol 2011; 11 (6): 525-31.

5. Müller S.M., Ege M., Pottharst A., Schulz A.S., Schwarz K., Friedrich W. Transplacentally acquired maternal $T$ lymphocytes in severe combined immunodeficiency: a study of 121 patients. Blood 2001; 98 (6): 1847-51.

6. Клинические рекомендации Министерства здравоохранения Российской Федерации. Первичный иммунодефицит: тяжелая комбинированная иммунная недостаточность. Год утверждения 2018

7. Венев Д.В, Дерипапа Е.В, Роппельт А.А, Лаберко А.Л, Абрамов Д.С., Варламова Т.В. и др. Лимфома как редкое осложнение тяжелой комбинированной иммунной недостаточности. Вопросы гематологии/онкологии и иммунопатологии в педиатрии. 2019; 18 (1): 104-11.

8. Pai S.-Y., Logan B.R., Griffith L.M., Buckley R.H., Parrott R.E., Dvorak C.C., et al. Transplantation Outcomes for Severe Combined Immunodeficiency, 20002009. N Engl J Med 2014; 371 (5): 43446.
9. Heimall J., Logan B.R., Cowan M.J., Notarangelo L.D., Griffith L.M., Puck J.M., et al. Immune reconstitution and survival of 100 SCID patients post-hematopoietic cell transplant: a PIDTC natural history study. Blood 2017; 130 (25): 2718-27.

10. Мухина А.А., Кузьменко Н.Б., Родина Ю.А., Кондратенко И.В., Бологов А.А., Латышева Т.В. и др. Характеристика пациентов с первичными иммунодефицитными состояниями в Российской Федерации: от рождения до старости. Педиатрия 2019; 98 (3): 24-31.

11. Балашов Д.Н., Лаберко А.Л., Козловская С.Н., Радыгина С.А., Лившиц А.М., Воронин К.А. и др. Эффективность трансплантации гемопоэтических стволовых клеток от альтернативного донора на платформе технологии клеточного моделирования трансплантата у пациентов с первичными иммунодесицитами. Педиатрия 2020; 99 (2): 43-51.

12. Brown L., Xu-Bayford J., Allwood Z., Slatter M., Cant A., Davies E.G., et al. Neonatal diagnosis of severe combined immunodeficiency leads to significantly improved survival outcome: the case for newborn screening. Blood 2011; 117 (11): 3243-6.

13. Национальный календарь профилактических прививок Министерства здравоохранения Российской Федерации. Год утверждения - 2017.

14. Marciano B.E., Huang C.-Y., Joshi G., Rezaei N., Carvalho B.C., Allwood Z., et al. BCG vaccination in patients with severe combined immunodeficiency: Complications, risks, and vaccination policies. J Allergy Clin Immunol 2014; 133 (4): 1134-41.

15. Bernatowska E., Skomska-Pawliszak M., Wolska-Kuśnierz B., Pac M., Heropolitanska-Pliszka E., Pietrucha B., et al. BCG Moreau Vaccine Safety Profile and NK Cells-Double Protection Against Disseminated BCG Infection in Retrospective Study of BCG Vaccination in 52 Polish Children with Severe Combined Immunodeficiency. J Clin Immunol 2020; 40 (1): 138-46.
16. Laberko A., Yukhacheva D., Rodina Y., Abramov D., Konovalov D., Radygina S., et al. BCG-Related Inflammatory Syndromes in Severe Combined Immunodeficiency After TCR $\alpha \beta^{+} / \mathrm{CD} 19^{+}$Depleted HSCT. J Clin Immunol 2020; 40 (4): 62536

17. Мухина А.А., Кузьменко Н.Б., Родина Ю.А., Хорева А.Л., Моисеева А.А., Швец О.В. и др. Эпидемиология первичных иммунодефицитов в Российской Федерации. Педиатрия 2020; 99 (2): 16-32.

18. Bousfiha A., Jeddane L., Picard C., Ailal F., Bobby Gaspar H., Al-Herz W., et al. The 2017 IUIS Phenotypic Classification for Primary Immunodeficiencies. J Clin Immunol 2018; 38 (1): 129-43.

19. Tangye S.G., Al-Herz W., Bousfiha A., Chatila T., Cunningham-Rundles C., Etzioni A., et al. Human Inborn Errors of Immunity: 2019 Update on the Classification from the International Union of Immunological Societies Expert Committee. J Clin Immunol 2020; 40 (1): 24-64.

20. Manzardo C., Guardo A.C., Letang E., Plana M., Gatell J.M., Miro J.M. Opportunistic infections and immune reconstitution inflammatory syndrome in HIV-1-infected adults in the combined antiretroviral therapy era: a comprehensive review. Exp Rev Anti-infective Ther 2015; 13 (6): 751-67.

21. Корсунский И.А., Гордукова М.А., Смирнова А.С., Мунблит Д.Б., Давыдова Н.В., Козлов И.Г. и др. Целесообразность неонатального скрининга первичных иммунодефицитных состояний. Российский медицинский журнал 2018; 26 (9): 29-32.

22. Корсунский И.А., Кудлай Д.А., Продеус А.П., Щербина А.Ю., Румянцев А.Г. Неонатальный скрининг на первичные иммунодефицитные состояния и Т-/В-клеточные лимфопении как основа формирования групп риска детей с врожденными патологиями. Педиатрия 2020; 99 (2): 8-15. 